\title{
Sérgio, Mário e a diversidade do modernismo brasileiro
}

\author{
Renato Martins
}

Monteiro, Pedro Meira (Org.). Mário de Andrade e Sérgio Buarque de Holanda: correspondência. São Paulo: Companhia das Letras/Instituto de Estudos Brasileiros/Edusp, 2012.

Ainda que a correspondência entre Sérgio Buarque de Holanda (1902-1982) e Mário de Andrade (1893-1945) tenha perdurado entre 1922 e 1944, não se pode dizer que, neste caso, o diálogo entre os dois nomes do modernismo brasileiro tenha sido constante. Trata-se de cartas trocadas de forma intermitente, que formam um conjunto epistolar pequeno, inaugurado quando os jovens amigos se dedicavam à circulação e recepção da revista Klaxon (1922-23), da qual, como sabemos, foram orgulhosos articuladores. Desde então poucas cartas foram trocadas. Algumas delas datam dos anos seguintes (1924 e 1928), época em que Buarque de Holanda lança a revista Estética (1924-1925) no Rio de Janeiro junto com Prudente de Moraes, neto; e Mário de Andrade, já às voltas com o significado da própria obra, espera do amigo uma crítica - jamais escrita - sobre ela. Outras ainda serão cultivadas entre 1931 e 1944, revelando algumas considerações de Sérgio sobre a poesia de Mário, ao mesmo tempo em que este elege o amigo seu consultor em matéria de história. ${ }^{1}$

Tais cartas foram recentemente organizadas por Pedro Meira Monteiro em Mário de Andrade e Sérgio Buarque de Holanda: correspondência, coletânea que tem o indiscutível mérito de reconhecer no conciso epistolário não a reunião de anedotas esparsas, mas uma janela que permite olhar e, sobretudo, repensar a problemática suscitada pelo modernismo brasileiro. Ao passar os olhos no livro tem-se a impressão de uma seleção e organização cuidadosamente elaborada das cartas, bem como da própria concepção da edição. A sensação vai se confirmando por meio da análise apurada da publicação, que é inaugurada por uma introdução, seguida de 31 cartas (doze escritas por Mário e dezenove por Sérgio), acompanhadas por notas explicativas que, em suma, podem ser tomadas como reflexão à parte. O leitor ainda tem acesso a outro rigoroso estudo assinado pelo organizador, inti-

1. As cartas encontram-se arquivadas no Instituto de Estudos Brasileiros da Universidade de São Paulo, onde se abriga o acervo pessoal de Mário de Andrade. Já no Arquivo Central da Universidade Estadual de Campinas pode-se ter acesso ao acervo bibliográfico e manuscrito de Sérgio Buarque de Holanda. De forma geral, a correspondência entre os dois autores está disponível para os pesquisadores há duas ou três décadas. 
tulado “'Coisas sutis, ergo profundas’: o diálogo entre Mário de Andrade e Sérgio Buarque de Holanda" (repartido por imagens selecionadas em sua maioria nos arquivos pessoais de ambos os autores, e sucedido por apêndices e uma cronologia de eventos significativos dos dois modernistas, que tornam ainda mais nítida a compreensão da correspondência). Enfim, por conta do juízo de Pedro Meira Monteiro, que acertadamente identificou nessas cartas uma importância de primeira grandeza, a coletânea pode ser qualificada como contribuição fundamental ao estudo daqueles dois gigantes da inteligência brasileira e, pois, do movimento artístico do qual foram assíduos participantes.

O volume retoma, afinal de contas, com indiscutível fôlego e originalidade, uma apreciação encontrada no pensamento social e literário sobre o modernismo brasileiro, a exemplo de Os donos do poder (1958), de Raymundo Faoro, e mais recentemente de Itinerário de uma falsa vanguarda (2010), de Antonio Arnoni Prado. Nesta perspectiva, o referido movimento pode ser percebido, em suma, pela óptica de duas vanguardas intelectuais, cada qual compartilhando distintos projetos estéticos e políticos: o modernismo da ordem e o da desordem. ${ }^{2}$ Não obstante as expressivas variações históricas e biográficas de tal divisão, por modernismo da ordem entenda-se o caso dos projetos conservadores, oriundos de grupos de intelectuais protagonizados, entre outros, por Graça Aranha (1868-1931) e Cassiano Ricardo (1895-1974), bem como por manifestos como o "Nhengaçu verde-amarelo" (1929). Ordem, assim, remete ao apego ao passado, às fórmulas literárias tradicionais e ao nacionalismo não raro xenófobo, conivente com as elites oligárquicas nativas. Modernismo da desordem, por sua vez, corresponde às aspirações tidas por radicais, contrárias ao academicismo e às sobrevivências oligárquicas, que, para seus adeptos, ancoravam o modernismo ao passado. Entre esses se encontram, em alguma medida, os próprios Sérgio Buarque e Mário de Andrade, mas também Alcântara Machado (1901-1935) e Oswald de Andrade (1890-1954), autor do paradigmático manifesto "Pau-Brasil" (1924).

Em "Coisas sutis, ergo profundas", Pedro Meira Monteiro salienta que a correspondência entre esses dois autores revela, primeiro, uma preocupação, contemporânea ao empuxo inicial do modernismo, em esboçar uma crítica estética à ordem: nas primeiras manifestações de Sérgio Buarque, aí incluídos o artigo "O lado oposto e outros lados"

2. Sobre Raimundo Faoro, ver particularmente: Raimundo Faoro, "Mudança e revolução", na segunda edição de Os donos do poder: formação do patronato político brasileiro. São Paulo/Porto Alegre: Globo, Edusp, 1975. E ainda, Antonio Arnoni Prado. Itinerário de uma falsa vanguarda: os dissidentes, a Semana de 22 e o Integralismo. São Paulo, Ed. 34, 2010. 
(1927) e, posteriormente, Raízes do Brasil, sua obra mais famosa, nota-se um incômodo com o arcaísmo que, no plano literário, ainda nos deixava presos ao estilo algo "pomposo"; "tudo se passa", diz Meira Monteiro, "como se um núcleo de vida resistisse, e devesse resistir sempre, às construções especiosas dos homens". ${ }^{3}$ Semelhante avaliação lê-se em Macunaíma (1928), obra que procura desvincular-se da pronta rigidez e formalidade das artes e letras que até então predominavam em nossa inteligência. Para tanto, ao invés de solucionar, procura problematizar a ideia de cultura brasileira, uma vez que, ainda nos termos de Meira Monteiro, não apresenta "resposta alguma para a questão identitária, e a própria [...] identidade se perde no momento em que o herói de nossa gente se dissolve".4

Por essas razões, um flerte com o surrealismo é fundamental naqueles anos para os dois amigos. Este, afinal de contas, parece fornecer um caminho para uma espécie de potência regressiva, que, amparada pelo mito, é valiosamente eficaz para suspender o sentido e reflorescer a desconfiança em relação à fixidez demasiada das fórmulas de linguagem. Em termos políticos, o incômodo de ambos se dirige à geração mais velha e, para eles, mais conservadora dos modernistas, bem afeita ao lastro patrioteiro e retrógrado da cultura. Aqui o alvo é diverso mas aparentado. Pode ser identificado na defesa feita por Elísio de Carvalho aos tempos patriarcais e à moral ociosa dos brasões e latifúndios; à celebração da raça e dos maiorais, advogada por Graça Aranha; ou ainda, noutros termos, aos programas nacionais de linha fascista, capitaneados por Plínio Salgado (1895-1975). Nestes casos, a arte deveria produzir um "brasileiro de subjetividade disciplinada" a fazer valer os mandamentos da tradição e dos poderes constituídos.

Mário de Andrade e Sérgio Buarque de Holanda: correspondência, contudo, nos mostra que a questão conflagrada pela "ordem" e "desordem" é evidentemente mais complexa, sobretudo quando acolhe uma ideia correlata, isto é, a ideia de construção. Cabe lembrar que o termo ocupa o pensamento e, mais ainda, o diálogo entre os dois missivistas. E aqui buscaremos somente resumir aquilo que nos parece uma diferença ao mesmo tempo sutil e renitente entre ambos, que, em termos mais amplos, também pode ajudar a revelar um

3. monteiro, Pedro Meira (Org.). Mário de Andrade e Sérgio Buarque de Holanda: correspondência. São Paulo: Companhia das Letras/Instituto de Estudos Brasileiros/Edusp, 2012, p. 202. Ver: HOLANDA, Sérgio Buarque de. "O lado oposto e outros lados". O Jornal. Rio de Janeiro, 1927, e Holanda, Sérgio Buarque de. Raízes do Brasil. Rio de Janeiro: José Olympio, 1936.

4. Id., p. 257. Ver: ANDRAdE, Mário de. Macunaíma: o herói sem nenhum caráter. São Paulo: Oficinas Gráficas de Eugenio Cupolo, 1928. 
grande impasse dentro do modernismo brasileiro. Ora, as cartas a certa altura atestam que, no limite, é impossível suspender por completo o sentido, uma vez que o próprio movimento artístico requer alguma ponta de formalização. Se Sérgio Buarque invariavelmente tolhe e se esquiva o mais possível de uma arte que, para ele, pouco fazia além de reproduzir o gesto formal e academizante que o movimento, nessa óptica, originalmente execrara; Mário de Andrade, por sua vez, "vive com particular dramatismo a tensão entre sua sensibilidade de artista, cônscio das exigências da escritura, e seus impulsos de intelectual à procura de melhor desempenho no papel de formador da nacionalidade e/ou no trabalho de construção social", nas palavras de João Luís Lafetá, lembradas por Meira Monteiro.

Longe de apresentar definições e respostas sobre o papel da construção encontrado nas cartas, a coletânea procura, isto sim, arregimentar uma hipótese segundo a qual, em torno do termo, estaria cifrado o grande limite do modernismo brasileiro. Pois no cenário de 1930 é impossível escapar a esta questão que, enquanto tal, não pode ser resumida pela disputa entre conservadores versus radicais (embora não deixe de preservar vínculos com tais distinções). É preferível tratá-la como desdobramento de uma nova época, inaugurada no Brasil pelas condições oriundas da Revolução de 1930, responsável, como bem lembra Antonio Candido, "por um movimento de unificação cultural, projetando na escala da nação fatos que antes ocorriam no âmbito das regiões": 6 este novo quadrante inevitavelmente obrigava o pensamento modernista brasileiro a enfrentar, com deslumbramento ou a contragosto, a questão nacional e moderna, o que por certo ocorre de múltiplas formas, vale recordar, por meio de propostas religiosas, encontradas em Literatura reacionária (1924), de Jackson de Figueiredo; pela reflexão sobre nossos traços psicológicos, realizada em Retrato do Brasil (1928), de Paulo Prado; ou, se preferirmos, por meio de nossa história corporal e sexual, registrada em Casa-grande \& senzala (1933), de Gilberto Freyre, dentre tantas outras.?

Em relação aos autores da correspondência, Pedro Meira Monteiro salienta que "os limites do modernismo estão dados, precisamente, no momento em que a construção se torna um anátema no pensamento de Sérgio Buarque, ao mesmo tempo em que

5. LAfETÁ, João Luís. 1930: a crítica e o modernismo. São Paulo: Duas Cidades/Ed. 34, 20oo, pp. 153-4. Apud monteiro, Pedro Meira (Org.), op. cit., p. 274.

6. CANDIDo, Antonio. "A Revolução de 1930 e a cultura”. Revista Novos Estudos - CEBRAP, n. 4. São Paulo, 1984, p. 27.

7. Ver: FIgueIRedo, Jackson de. Literatura reacionária. Rio de Janeiro: Centro Dom Vital, 1924; PRADo, Paulo. Retrato do Brasil: ensaio sobre a tristeza brasileira. São Paulo: Duprat-Mayença, 1928; FREYRE, Gilberto. Casa-grande \& senzala. Rio de Janeiro: Maia \& Schmidt, 1933. 
é para ela que caminha, malgrado a si mesmo, o pensamento de Mário de Andrade". Uma respeitosa e madura situação paradoxal que, a julgar pelo quebra-cabeça contido nas cartas, é alargada à medida que o criador de Macunaíma vai revelando ao colega sua predição pelo catolicismo e, com efeito, a crença no papel escatológico da literatura na formação de um país. Não que Mário acreditasse no fim dos tempos, numa teologia algo simplista do desenvolvimento do homem, ou mesmo em doutrina. O que não parecia suportar, a bem da verdade, era a suspensão integral do sentido. Sérgio Buarque, por outro lado, parece manter-se o tempo todo adepto de uma "iconoclastia" de termos e limites imprecisos, que futuros pesquisadores poderiam enfim aclarar.

A senda, afinal, foi vigorosamente aberta por essa edição de Mário de Andrade e Sérgio Buarque de Holanda: correspondência. É preciso adentrá-la, uma vez que a admirável relação artesanal e indiciosa de Pedro Meira Monteiro com a pesquisa e reunião destas cartas nos coloca a par do que o antropólogo Clifford Geertz denomina de "diversidade do pensamento moderno". ${ }^{9}$ Ora, a atmosfera de unificação cultural gerada pela mítica década de 1930 no Brasil foi, sim, efetiva, mas não implicou o fim das diferenças de perspectivas e projetos no modernismo. Inclusive no caso daquelas personagens que, como Sérgio e Mário, compartilham de fato um cosmopolitismo esclarecido e uma trajetória biográfica que, em relação ao movimento, os colocavam em perspectivas bastante similares. Isso não impede de pensarmos, ao mesmo tempo, nas diferenças intelectuais que estes dois amigos poderiam alimentar, dentro dele. Estamos diante de um jogo complexo, cujas sendas, vale reiterar, foram abertas de forma lapidar; agora elas pedem que sejam desvendadas com merecido arroubo.

Renato Martins é doutorando em História Social pela Universidade de São Paulo(USP, São Paulo, SP, Brasil), onde desenvolve uma pesquisa sobre a obra historiográfica de Sérgio Buarque de Holanda. Organizador do livro Encontros: Sérgio Buarque de Holanda. Rio de Janeiro: Azougue Editorial, 2009.

8. Monteiro, Pedro Meira (Org.), op. cit., p. 172.

9. Ver: GeERTz, Clifford. "Como pensamos hoje: a caminho de uma etnografia do pensamento moderno”. In: O saber local: novos ensaios em antropologia interpretativa. Rio de Janeiro: Vozes, 2012. 